\title{
Differences Effectiveness of Behavioral Counseling Modeling Technique with Aversi Technique to Self Endurance
}

\author{
Perbedaan Efektivitas Model Konseling Behavioral Teknik Modeling dengan Teknik Aversi \\ terhadap Self Endurance
}

\author{
Dewa Gede Agung Permana Putra ${ }^{1}$, Dewi Arum $\mathrm{WMP}^{2}$, I Ketut Dharsana ${ }^{3}$ \\ ${ }^{123}$ Universitas Pendidikan Ganesha \\ e-mail: iketut.dharsana@undiksha.ac.id
}

Received February 14, 2017

Revised April 09, 2017

Accepted Mei 30, 2017

Published Online June 30, 2017

\section{Conflict of Interest Disclosures: \\ The authors declare that they have no significant competing financial, professional or personal interests that might have influenced the performance or presentation of the work described in this manuscript.}

\section{(c) (1)}

This is an open access article distributed under the Creative Commons 4.0 Attribution License which permits unrestricted use, distribution, and reproduction in any medium, provided the original work is properly cited. $\odot 2017$ by author

\begin{abstract}
The purpose of this research is to know the effectiveness of behavioral counseling model of modeling technique to experiment class I with students given conventional treatment to stabilize Self Endurance students of SMK N 2 Singaraja, to know effectiveness of behavioral counseling model aversi technique to experiment class II with students given treatment conventionally to stabilize Self Endurance student of SMK N 2 Singaraja, to know the difference of effectiveness of behavioral counseling model of modeling technique with aversi technique to Self Endurance of SMK N 2 Singaraja students. The process of collecting data in this study using observation sheet, interview sheet, diary and Self Endurance questionnaire. This research is a quasi research ("Quasi Experiment"), data analysis method used is t-test. From this research, modeling technique is more effective than the aversion model of behavioral counseling model in stabilizing Self Endurance of class X students of SMK Negeri 2 Singaraja.
\end{abstract}

Keywords: aversi, behavioral, modeling, self endurance.

\begin{abstract}
Abstrak: Tujuan dari penelitian ini adalah untuk mengetahui efektivitas model konseling behavioral teknik modeling terhadap kelas ekperimen I dengan siswa yang diberikan perlakuan secara konvensional untuk menstabilisasi Self Endurance siswa SMK N 2 Singaraja, untuk mengetahui efektivitas model konseling behavioralteknik aversi terhadap kelas ekperimen II dengan siswa yang diberikan perlakuan secara konvensional untuk menstabilisasi Self Endurance siswa SMK N 2 Singaraja, untuk mengetahui perbedaan efektivitas model konseling behavioral teknik modeling dengan teknik aversi terhadap Self Endurance siswa SMK N 2 Singaraja. Proses pengumpulan data dalam penelitian ini menggunakan lembar observasi, lembar wawancara, buku harian dan kuesioner Self Endurance. Penelitian ini merupakan penelitian semu ("Quasi Eksperiment"), metode analisis data yang digunakan adalah ttest. Dari penelitian ini teknik modeling lebih efektif dibandingkan dengan teknik aversi model konseling behavioral dalam menstabilisasi Self Endurance siswa kelas X SMK Negeri 2 Singaraja.
\end{abstract}

Kata Kunci: aversi, behavioral, modeling, self endurance

How to Cite: Putra, D. G. A. P., WMP, D. A., \& Dharsana, I. K. (2017). Differences Effectiveness of Behavioral Counseling Modeling Technique with Aversi Technique to Self Endurance. Bisma, 1(1), 50-59. https://doi.org/10.23887/128332017 


\section{Pendahuluan}

Pengamatan peneliti terhadap Self Endurance siswa kelas X SMK Negeri 2 Singaraja, peneliti melihat sebagian siswa menunjukkan Self Endurance terdapat siswa menunjukan Self Endurance seperti mampu mengerjakan suatu pekerjaan sampai selesai, memiliki usaha menyelesaikan pekerjaan sampai tuntas, mampu bekerja keras pada suatu tugas, dan memiliki kesabaran dalam menyelesaikan suatu pekerjaan (Basset Jr \& Howley, 2000; Coetsee, 2015; Guillermo, 2010; Hoff, Kähler, \& Helgerud, 2006; Jumaquioardales, 2014; Kroff, 2005; Ponce, 2008; Schmidt, Prommer, Steinacker, \& Boning, 2006; Stamina, 2014).

Disisilain, terdapat sebagian siswa yang menunjukkan Self Endurance yang rendah seperti kurang mampu mengerjakan suatu pekerjaan sampai selesai, kurang memiliki usaha menyelesaikan pekerjaan sampai tuntas, kurang mampu bekerja keras pada suatu tugas, serta kurang memiliki kesabaran dalam menyelesaikan suatu pekerjaan.

Menurut Dharsana (2014:1001), Self Endurance adalah kebutuhan untuk tahan mengatasi rintangan meliputi mengerjakan suatu pekerjaan sampai selesai, berusaha menyelesaikan pekerjaan sampai tuntas, bekerja keras pada suatu tugas. Berdasarkan definisi tersebut, maka Self Endurance dalam hal ini mengandung 3 aspek yaitu (1) mampu mengerjakan suatu pekerjaan sampai selesai, (2) Memiliki usaha menyelesaikan pekerjaan sampai tuntas, (3) Mampu bekerja keras pada suatu tugas.

Dalam kamus umum Inggris - Indonesia, self artinya diri dan Endurance artinya ketahanan dan kesabaran. Untuk itu, dapat diketahui bahwa SelfEndurance adalah pribadi yang memiliki ketahanan dan kesabaran. Berdasarkan definisi tersebut maka Self Endurance dalam hal ini mengandung 2 aspek yaitu 1) mampu menjadi pribadi yang memiliki ketahanan, 2) mampu menjadi pribadi yang memiliki kesabaran.

Berdasarkan pemaparan definisi tersebut, maka dalam penelitian ini yang dimaksud dengan Self Endurance adalah kebutuhan individu untuk mampu bertahan dan memiliki kesabaran dalam dalam mengatasi rintangan seperti mengerjakan suatu pekerjaan sampai selesai, berusaha menyelesaikan pekerjaan sampai tuntas, bekerja keras pada suatu tugas, memiliki kesabaran dalam menyelesaikan suatu pekerjaan. Untuk itu, dalam hal ini Self Endurance mengandung aspek-aspek: 1) mampu mengerjakan suatu pekerjaan sampai selesai, 2) memiliki usaha menyelesaikan pekerjaan sampai tuntas, 3) mampu bekerja keras pada suatu tugas, dan 4) memiliki kesabaran dalam menyelesaikan suatu pekerjaan.

Dharsana (2010: 258) mendefi nisikan bahwa teori konseling Behavioral adalah proses secara menyeluruh dan juga suatu usaha berdasarkan percobaan untuk menjelaskan prinsip dan kaidah-kaidah bagaimana tingkah laku manusia dipelajari. Menurut Watson (dalam Rosjidan, 1988:230) Konseling behavioral adalah konseling yang dilakukan dengan pengkondisian sehingga terbentuk kebiasaankebiasaan baru yang berguna bagi hidup individu.Menurut Winkell (dalam Arintoko, 2011: 35) Konseling behavioristik merupakan corak konseling yang diharapkan dapat menghasilkan perubahan yang nyata dalam perilaku konseli.

Menurut Corey ( dalam Dharsana $2014: 515$ ) teori behavioral adalah teori konseling yang menekankan pada tingkah laku manusia yang pada dasarnya dibentuk dan ditentukan oleh lingkungan dan segenap tingkah lakunya, itu dipelajari dan diperoleh karena proses latihan.

Menurut Watson (dalam Dharsana 2014 : 584) "Konseling behavioral adalah konseling yang dilakukan dengan pengkondisian sehingga terbentuk kebiasaan-kebiasaan baru yang berguna bagi hidup individu". Sedangkan menurut Winkell (dalam Dharsana 2014 : 584) "Konseling behavioristik merupakan corak konseling yang diharapkan dapat menghasilkan perubahan yang nyata dalam perilaku konseli".

Dharsana (2014:215) menyatakan bahwa kebaikan dari model konseling Behavioral adalah teori konseling Behavioral memandang bahwa tingkah laku itu tertib dan bahwa eksperimen yang dlkendalikan dengan cermat, pendekatan teori ini tidak mengurangi asumsi - asumsi fi losofis tertentu tentang manusia secara langsung, setiap orang dipandang memiliki kecendrungan positif, negatif yang sama.Dasar alasannya ialah bahwa segenap tingkah laku adalah dipelajari (learned), termasuk tingkah laku yang maladaptif (salah suai)(Bannink, 2004; Bello, 2015; Calvano, 2004; Damayanti \& Aeni, 2016; Fran, 2007a, 2007b; Guirado, 2008; Had \& Ad, n.d.; Hoog, n.d.; Mustafa, n.d.; Not, 2008; "Pedagogika," 2007; Rollnick \& Miller, 2003; Sampieri, Collado, \& Lucio, 2006; Whitlock, Orleans, Pender, \& Allan, 2002). Jika tingkah laku neurotik Ieamed, maka ia bisa unleamed (dihapus dari ingatan), dan tingkah laku yang lebih efektif bisa diperoleh 
Definisi tersebut di atas dapat disimpulkan bahwa konseling Behavioral adalah proses dalam menstabilisasi Self Endurance dengan teknik modeling dan teknik Aversi, prosedur dan langkah, skill konseling melalui bimbingan klasikal, bimbingan kelompok, konseling kelompok, konseling individual yang telah di tentukan.

\section{Metode}

Dalam penelitian ini, desain penelitian yang digunakan adalah Nonequivalent Control Group Desain. Menurut Dantes, (2012:97)Nonequivalent Control Group Desainmerupakan model eksperimen semu (quasi ekperiment). Desain ini sangat sering digunakan dalam penelitian pendidikan dan penelitian perilaku (behavioral) lainnya. Pada penelitian ini, sering digunakan intact group, seperti, kelas, dimana simple random tidak dapat digunakan.

Teknik pengumpulan data dalam penelitian yaitu 1) Teknik Pengamatan (observasi), 2) Teknik Wawancara, 3) Kuesioner, 4) Dokumen dan Artefak. Populasi dalam penelitian ini adalah siswa kelas X di SMK Negeri 2 Singaraja dengan jumlah 3 kelas.

Langkah-langkah penelitian ini meliputi: 1) Persiapan eksperimen (menyusun istrumen, mengurus Izin penelitian, melakukan observasi awal, menguji instrumen kuesioner self endurance uji Coba Instrumen, dan menyusun jadwal pelaksanaan eksperimen). 2) Tahap Pelaksanaan Eksperimen (pelaksanaan pre test, pelaksanaan layanan meliputi bimbingan klasikal, bimbingan kelompok, konseling kelompok, konseling individu). 3) Tahap Akhir (pemberian post-test, analisis data).

Teknik pengumpulan data dalam penelitian yaitu 1) Teknik Pengamatan (observasi), 2) Teknik Wawancara, 3) Kuesioner, 4) Dokumen dan Artefak.

Data-data yang terkumpul melalui lembar observasi, lembar wawancara, dan buku harian akan dianalisis menggunakan teknik Deskriptif Kualitatif. Kemudian data-data yang terkumpul melalui kuesioner self endurance, dianalisis menggunakan teknik Deskriptif Kuantitatif menggunakan rumus t-test.

\section{Hasil dan Pembahasan}

Variabel yang dikaji dalam penelitian ini adalah bakat verbal siswa di kelas X Boga3, X Boga4, dan X Boga5 ngaraja. Data hasil observasi awal terhadap sampel bahwa siswa yang menunjukkan gejala-gejala bakat verbalyang bersifat positif (+) sebanyak 66 orang dan yang yang bersifat negatif (-) sebanyak 34 orang.

Berdasarkan tabel 4.1 di atas, dapat diketahui bahwa terdapat siswa yang menunjukkan gejala-gejala Self Endurance yang bersifat positif (+) maupun negatif (-). Secara kuantitatif, jumlah siswa yang menunjukkan gejala-gejala Self Endurance yang bersifat positif $(+)$ sebanyak 75 orang dan yang menunjukkan gejala-gejala Self Endurance yang bersifat negatif (-) sebanyak 44 orang. Secara persentase, $58 \%$ siswa menunjukkan gejala-gejala Self Endurance yang bersifat positif $(+)$ dan $42 \%$ siswa menunjukkan gejala-gejala Self Endurance yang bersifat negatif (-). Sehingga, dari data awal ini maka dapat diketahui bahwa kelompok siswa yaitu X Boga3 , X Boga4, dan X Boga5, lebih banyak menunjukkan gejala - gejla Self Endurance yang bersifat positif $(+)$ daripada yang bersifat negatif $(-)$. Selanjutnya skor buku harian siswa kelompok eksperimen I dimasukkan ke dalam grafik harian. Setelah diketahui harian buku harian siswa, selanjutnya data tersebut dimasukkan ke dalam data buku harian mingguan. Selanjutnya skor buku harian mingguan siswa kelompok eksperimen I dimasukkan ke dalam grafik mingguan.

Perbedaan Model Konseling Behavioral Teknik Modeling Terhadap Kelas Kelompok Ekperimen I dengan Kelompok Kontrol Yang Mendapat Perlakuan Konvensional untuk Menstabilikan Self Endurance siswa SMK N 2 Singaraja.

Siswa kelas X Boga3 SMK Negeri 2 Singaraja, berdasarkan hasil pengamatan telah menunjukkan gejala-gejala seperti kurang mampu mengerjakan suatu pekerjaan sampai selesai, kurang memiliki usaha menyelesaikan pekerjaan sampai tuntas, kurang mampu bekerja keras pada suatu tugas, dan kurang memiliki kesabaran dalam menyelesaikan suatu pekerjaan. Gejala-gejala tersebut diatas, merupakan gejala Self Endurance yang rendah. Sehingga, gejala-gejala tersebut penting untuk diperhatikan agar siswa memiliki pribadi Endurance yang tinggi. 
Untuk melakukan "treatment" terhadap Self Endurance siswa yang rendah tersebut, dalam layanan bimbingan konseling terdapat berbagai macam teori konseling yang dapat diaplikasikan salah satunya yaitu teori konseling Behavioral.Model Konseling Behavioral adalah konseling yang dilakukan dengan pengkondisian sehingga terbentuk kebiasaan-kebiasaan baru yang berguna bagi hidup individu, kondisinya saat ini dengan prosedur dan langkah yang telah ditentukan. Secara praktis, pengaplikasian model konseling behavioral ini memerlukan teknik. Dalam hal ini, untuk memberikan "treatment" terhadap Self Endurance siswa, teknik yang digunakan adalah teknik Modeling

Teknik modeling cara melalui observasi permodelan, mengobservasi seseorang lainnya sehingga seseorang tersebut membentuk ide dan tingkah laku, kemudian dijelaskan sebagai panduan untuk bertindak yang berkaitan dengan Self Endurance 1) mampu mengerjakan suatu pekerjaan sampai selesai, 2) memiliki usaha menyelesaikan pekerjaan sampai tuntas, 3) mampu bekerja keras pada suatu tugas, dan 4) memiliki kesabaran dalam menyelesaikan suatu pekerjaan(Adiputra, 2015; Gh, Nampower, \& Rekeningkunde, 2012; Giunta \& Watson, 1998; Mar, Hasanah, \& Saraswati, 2014; Picone, 1993; Tera \& Ha, 1995; Xhaferaj \& Hasanaj, 2012)

Teknik kursi kosong diaplikasikan dalam model konseling behavioral berupa layanan bimbingan klasikal, bimbingan kelompok, konseling kelompok, dan konseling individu pada siswa kelas X Boga3 SMK Negeri 2 Singaraja sebagai kelompok eksperimen I.

Hasil observasi yang dilakukan dalam setiap pelaksanaan layanan, menunjukkan bahwa terjadi peningkatan umlah siswa yang mengalami Self Endurance yang rendah.Hasil observasi dalam bimbingan klasikal menemukan 9 orang siswa yang menunjukkan gejala Self Endurance yang rendah yang selanjutnya direkomendasikan mengikuti bimbingan kelompok.Kemudian hasil observasi dalam bimbingan kelompok menemukan 6 orang siswa menunjukkan gejala Self Endurance yang rendah yang selanjutnya direkomendasikan mengikuti konseling kelompok. Selanjutnya hasil observasi dalam konseling kelompok menemukan 1 orang siswa menunjukkan gejala Self Endurance yang rendah yang selanjutnya direkomendasikan mengikuti konseling individu. Setelah dilakukan konseling individual, siswa sudah mampu menunjukkan gejala-gejala Self Endurance yang tinggi. Dari data hasil observasi tersebut, dapat diketahui bahwa setelah diberikan "treatment" model konseling Behavioral teknik modeling, terjadi peningkatan Self Self Endurance yang rendah. Sehingga, jumlah siswa yang mengalami gejala-gejala Self Endurance yang rendah dapat berkurang.

Temuan empiris pada penelitian ini menyatakan bahwa teknik modeling dalam model konseling Gestalt efektif terhadap Self Endurance siswa kelas X Boga3. Hasil uji F diketahui bahwa kedua varians tidak homogen dimana ternyata $\mathrm{F}$ hitung $>\mathrm{F}$ tabel $(36,08>1,69)$. Kemudian dilakukan uji t didapatkan hasil bahwa Harga t hitung diperoleh 5,39 dan Harga t tabel sebesar 1,684. Jika dibandingkan Harga $t$ hitung dengan Harga $t$ tabel didapatkan bahwa Ternyata $t$ hitung $>$ Harga $t$ tabel dengan $\mathrm{db} 40$ dan 409 dan taraf siginifikansi 5\% $(\alpha=0,05)$. Ini berarti bahwa Ho ditolak dan Ha diterima. Untuk itu, hipotesis ke pertama yaitu ada perbedaan model konseling behavioral teknik modeling terhadap kelompok ekperimen I dengan siswa yang mendapat perlakuan konvensional untuk menstabilisasi Self Endurance Siswa SMK N 2 Singaraja diterima. Sehingga ada perbedaan efektivitas model konseling behavioral teknik modeling terhadap siswa yang mendapat perlakuan konvensional untuk menstabilisasi Self Endurance siswa SMK N 2 Singaraja. Teknik modeling efektif untuk menstabilisasi Self Endurance karena teknik ini mampu membantu konseli untuk menyelesaikan permasalahan yang terdahulu sehingga konseli dapat mengetahui bagaimana cara merubah tingkah barunya sehingga siswa yang memiliki Self Endurance dapat di stabilisasi dengan bantuan simbol modeling yaitu dengan video yang digunakan untuk mencari cara untuk merubah tingkah lakunya tersebut.

Perbedaan Model Konseling Behavioral Teknik Aversi Terhadap Kelompok Ekperimen II dengan Kelompok Kontrol Yang Mendapat Perlakuan Konvensional Untuk Menstabilisasi Self Endurance Siswa SMK N 2 Singaraja.

Siswa kelas X Boga4 SMK Negeri 2 Singaraja, berdasarkan hasil pengamatan telah menunjukkan gejala-gejala seperti kurang mampu mengerjakan suatu pekerjaan sampai selesai, kurang memiliki usaha menyelesaikan pekerjaan sampai tuntas, kurang mampu bekerja keras pada suatu tugas, dan kurang memiliki kesabaran dalam menyelesaikan suatu pekerjaan.

Gejala-gejala tersebut diatas, merupakan gejala Self Endurance yang rendah.Sehingga, gejala-gejala tersebut penting untuk diperhatikan agar siswa memiliki pribadi Endurance yang stabil. 
Untuk melakukan "treatment" terhadap Self Endurancesiswa yang rendah tersebut, dalam layanan bimbingan konseling terdapat berbagai macam teori konseling yang dapat diaplikasikan salah satunya yaitu teori konseling behavioral .Model Konseling behavioral adalah proses secara menyeluruh dan juga suatu usaha berdasarkan percobaan untuk menjelaskan prinsip dan kaidah-kaidah bagaimana tingkah laku manusia dipelajari. Secara praktis, pengaplikasian model konseling behavioral ini memerlukan teknik. Dalam hal ini, untuk memberikan "treatment" terhadap Self Endurance siswa kelas X Boga4 , teknik yang digunakan adalah teknik aversi.

Teknik aversi adalah metode-metode yang paling kontroversial karena teknik ini membuat kondisi dimana orang-orang melakukan apa yang diharapkan dari mereka dalam rangka menghindari konsekuensikonsekuensi aversif seperti perusahaan-perusahaan menggunakan pemecatan dan penangguhan pembayaran upah, serta pemerintah menggunakan denda dan hukuman penjara (Analise, Koolhidraat, \& Hons, 2006; Beukes, 2012; Economia, 1997; Giuseppe, Ottavio, Simone, \& Simone, n.d.; Mengalami, Identitas, \& Gig, n.d.)

.Dalam hal ini, teknik aversi diaplikasikan dalam model konseling behavioral berupa layanan bimbingan klasikal, bimbingan kelompok, konseling kelompok, dan konseling individu pada siswa kelas X Boga4 SMK Negeri 2 Singaraja sebagai kelompok eksperimen II.

Hasil observasi yang dilakukan dalam setiap pertemuan, menunjukkan bahwa terjadi peningkatan jumlah siswa yang mengalami Self Endurance yang rendah.Hasil observasi dalam bimbingan klasikal menemukan 9 orang siswa menunjukkan gejala Self Endurance yang rendah yang selanjutnya direkomendasikan mengikuti bimbingan kelompok.Kemudian hasil observasi dalam bimbingan kelompok menemukan 6 orang siswa menunjukkan gejala Self Endurance yang rendah yang selanjutnya mengikuti konseling kelompok.Kemudian hasil observasi dalam konseling kelompok menemukan 1 orang siswa menunjukkan gejala Self Endurance yang rendah yang selanjutnya direkomendasikan mengikuti konseling individu. Setelah konseling individu dilaksanakan, siswa sudah mampu menunjukkan gejala Self Self Endurance yang tinggi.Dari data hasil observasi tersebut, dapat diketahui bahwa setelah diberikan "treatment"model konseling behavioral teknik aversi, terjadi peningkatan Self Endurance yang rendah. Sehingga, jumlah siswa yang mengalami gejala-gejala Self Self Endurance yang rendah dapat berkurang.

Temuan empiris pada penelitian ini menyatakan bahwa teknik aversi dalam model konseling behavioral efektif terhadap Self Endurance siswa kelas X Boga4 . Hasil uji F diketahui bahwa kedua varians tidak homeogen dimana $\mathrm{F}$ hitung $>\mathrm{F}$ tabel $(21,00>1,69)$. Kemudian dilakukan uji t didapatkan hasil bahwa Harga $t$ hitung diperoleh 2,58 dan Harga $t$ tabel sebesar 1,68. Jika dibandingkan Harga $t$ hitung dengan Harga $t$ tabel didapatkan bahwa 2,58 $>1,68$ artinya Harga $t$ hitung $>$ Harga $t$ tabel dengan db 39 dan 39 dan taraf siginifikansi 5\% $(\alpha=0,05)$. Ini berarti bahwa Ho ditolak dan Ha diterima. Untuk itu, hipotesis ke dua perbedaan efektivitas model konseling behavioral teknik aversi terhadap kelompok ekperimen II dengan siswa yang mendapatkan perlakuan konvensional untuk menstabilisasi Self Endurance siswa SMK N 2 Singaraja diterima. Sehingga dapat diketahui bahwa efektivitas model konseling behavioral teknik aversi terhadap kelompok ekperimen II dengan siswa yang mendapatkan perlakuan konvensional untuk menstabilisasi Self Endurance siswa kelas SMK Negeri 2 Singaraja. Teknik Aversi efektif untuk menstabilisasi Self Endurance Siswa karena dengan diberikan hukuman kepada siswa dapat menjadikan siswa motivasi agar tidak mengulangi kesalahan yang sama, dan di harapkan dengan menggunakan teknik aversi ini siswa dapat merubah tingkah lakunya menjadi lebih baik dari sebelumnya.

\section{Perbedaan Efektivitas Model Konseling Behavioral Teknik Modeling dengan Teknik Aversi untuk menstabilisasi Self Endurance Siswa SMK N 2 Singaraja}

Model Konseling behavioral merupakan observasi permodelan, mengobservasi seseorang lainnya sehingga seseorang tersebut membentuk ide dan tingkah laku, kemudian dijelaskan sebagai panduan untuk bertindak". Bandura juga menegaskan bahwa modeling merupakan konsekuensi perilaku meniru orang lain dari pengalaman baik pengalaman langsung maupun tidak langsung, sehingga reaksi-reaksi emosional danrasa takut seseorang dapat dihapuskan.Secara praktis, pengaplikasian model konseling behavioral ini memerlukan teknik. Dalam hal ini, untuk memberikan "treatment" terhadap Self Endurance siswa, teknik yang digunakan adalah teknik modeling dan teknik aversi.

Teknik modelingobservasi permodelan, mengobservasi seseorang lainnya sehingga seseorang tersebut membentuk ide dan tingkah laku, kemudian dijelaskan sebagai panduan untuk bertindak". Bandura juga 
menegaskan bahwa modeling merupakan konsekuensi perilaku meniru orang lain dari pengalaman baik pengalaman langsung maupun tidak langsung, sehingga reaksi-reaksi emosional danrasa takut seseorang dapat dihapuskan. Dalam hal ini, teknik modeling diaplikasikan dalam model konseling behavioral berupa layanan bimbingan klasikal, bimbingan kelompok, konseling kelompok, dan konseling individu pada siswa kelas X Boga4 SMK Negeri 2 Singaraja sebagai kelompok eksperimen I.

Teknik Aversi metode-metode yang paling kontroversial karena teknik ini membuat kondisi dimana orang-orang melakukan apa yang diharapkan dari mereka dalam rangka menghindari konsekuensikonsekuensi aversif seperti perusahaan-perusahaan menggunakan pemecatan dan penangguhan pembayaran upah, serta pemerintah menggunakan denda dan hukuman penjara. Dalam hal ini, teknik aversi diaplikasikan dalam model konseling behavioral berupa layanan bimbingan klasikal, bimbingan kelompok, konseling kelompok, dan konseling individu pada siswa kelas X Boga4 SMK Negeri 2 Singaraja sebagai kelompok eksperimen II.

Teknik Modeling dengan teknik aversi telah terbukti efektif dalam menstabilisasi Self Endurance siswa pada kelompok eksperimen. Dari hasil observasi dan pengujian data kuesioner Self Endurance pada "pretest" dan "post-test", terdapat perbedaan yang signifikan. Sehingga, gejala-gejala Self Endurance siswa yang rendah mengalami peningkatan.

Temuan empiris pada penelitian ini, menyatakan bahwa terdapat perbedaan efektivitas antara teknik modeling dengan teknik aversi model konseling behavioral terhadap Self Endurance siswa. Hasil uji $\mathrm{F}$ menyatakan bahwa kedua varian tidak homogen dimana Fhitung > Ftabel yaitu 36,08> 1,69 (db 40 dan 40 dengan $\alpha=0,05$ ). Dari hasil uji t bahwa Harga t hitung diperoleh 4,17 dan Harga t tabel sebesar 2,03 Jika dibandingkan Harga $t$ hitung dengan Harga t tabel didapatkan bahwa 2,80> 1,68 artinya Harga $t$ hitung $>$ Harga $t$ tabel dimana db 38 dan 39dengan taraf siginifikansi $5 \%(\alpha=0,05)$. Ini membuktikan bahwa, terdapat perbedaan antara teknik modeling dengan teknik aversi model konseling behavioral terhadap Self Endurance siswa. Dari hasil rerata hitung, didapatkan $\overline{X_{1}}=11,30>\overline{X_{2}}=4,775$, artinya nilai rerata hitung teknik modeling lebih besar daripada teknik aversi. Ini berarti Ho ditolak dan Ha diterima. Untuk itu hipotesis ketiga yaitu terdapat perbedaan efektivitas model konseling behavioral teknik modeling dengan teknik aversi untuk menstabilisasi Self Endurance siswa SMK Negeri 2 Singaraja diterima. Sehingga dapat diketahui bahwa terdapat perbedaan efektivitas model konseling behavioral teknik modeling dengan teknik aversi untuk menstabilisasi Self Endurance siswa SMK Negeri 2 Singaraja dimana teknik modeling lebih efektif terhadap Self Endurance siswa SMK N 2 Singaraja. Teknik modeling lebih efektif dari pada teknik aversi karena teknik modeling lebih secara langsung siswa mencontoh perilaku untuk mengubah tingkah laku khususnya dari siswa yang memiliki Self Endurance mengalami peningkatan, siswa juga secara langsung bisa mencari contoh bagaimana untuk mengatasi permasalahan yang di alami oleh siswa, dan secara langsung juga konselor dapat melihat perubahan yang sudah di tentukan, namun sebaliknya dengan teknik aversi, teknik aversi sangat sulit untuk melihat dan mencari tahu perubahannya, sering kali siswa mengatakan tidak sesuai dengan keadaannya sehingga kemungkinan siswa tersebut dapat terhindar dari hukuman yang sudah di tentukan,maka dari pada itu teknik modeling sangat efektif untuk menstabilisasi Self Endurance sehingga konseli mudah untuk menerapkan teknik tersebut dan dapat membantu konseli untuk menstabilisasi Self Endurance.

\section{Kesimpulan}

Berdasarkan hasil penelitian maka dapat diperoleh beberapa kesimpulan, diantaranya yaitu:

1. Terdapat perbedaan efektivitas model konseling behavioral teknik modeling dengan teknik aversi untuk menstabilisasi Self Endurance siswa SMK Negeri 2 Singaraja.

2. Teknik modeling lebih efektif dari pada teknik aversi karena teknik modeling lebih secara langsung siswa mencontoh perilaku untuk mengubah tingkah laku khususnya dari siswa yang memiliki Self Endurance mengalami peningkatan.

3. Teknik aversi sangat sulit untuk melihat dan mencari tahu perubahan pada siswa.

4. Teknik modeling sangat efektif untuk menstabilisasi Self Endurance sehingga konseli mudah untuk menerapkan teknik tersebut dan dapat membantu konseli untuk menstabilisasi Self Endurance. 


\section{Referensi}

Afandi, R. (2012). Stage Hypnosis With Magic. Jakarta: PT Sarana Tutorial Nurani.

Adiputra, S. (2015). Penggunaan Teknik Modeling Terhadap Perencanaan Karir Siswa. Jurnal Fokus Konseling, 1(1), 45-56.http://ejournal.stkipmpringsewu-lpg.ac.id/index.php/fokus/article/view/70

Alwi, Hasan. (2015). Kamus Besar Bahasa Indonesia. Jakarta: Balai Pustaka.

Arikunto, Suharsimi. (2006). Prosedur Penelitian Suatu Pendekatan Praktek. Jakarta: PT Rineka Cipta.

Bannink, F. (2004). therapie: een vorm van gedragstherapie. Retrieved from http://www.fredrikebannink.com/bannink/wpcontent/uploads/2011/03/Art_De_kracht_van_oplossingsgerichte_therapie.pdf

Basset Jr, D. R., \& Howley, E. T. (2000). Limiting factors for maximum oxygen uptake and determinants of endurance performance. Medicine and Science in Sports and Exercise, 32(1), 70-84. Retrieved from http://www.unm.edu/ rrobergs/478LimitingFactorsReview.pdf

Beukes, J. (2012). Analitiese konsepte in middel-foucault. HTS Teologiese Studies / Theological Studies, 1-17. https://doi.org/10.4102/hts.v68i1.1035

Badri, Sutrisno. 2012.Metode Statistik untuk Penelitian Kuantitatif. Yogyakarta: Ombak (Anggota IKAPI)

Bungin, Burhan. 2011. Metodelogi Penelitian Kuantitatif, komunikasi, ekonomi dan kebijakan public serta ilmuilmu sosial lainnya. Jakarta: Kencana Perdana Media Group.

Calvano, F. (2004). counseling, (1989), 1-15.

Coetsee, C. (2015). the Relation of Exercise Training Mode, Brain Oxygenation and Cognition in Healthy Older Adults, (December). Retrieved from http://ir.nrf.ac.za/handle/10907/422

Corey, Gerald. (1995). Teori dan Praktek Konseling \& Psikoterapi. Bandung: PT. Refika Aditama

Dantes, Nyoman. (2012). Metode Penelitian. Yogyakarta: CV Andi Offset

Dharsana, Ketut. (2013a). Modul Teori-Teori Konseling.Singaraja: Jurusan Bimbingan Konseling, FIP UNDIKSHA

- (2013b). Pengembangan Pribadi Konselor. Singaraja: Jurusan Bimbingan Konseling, FIP UNDIKSHA

(2014). Model-Model Teori, Teknik, Skill Bimbingan Konseling untuk Penulisan RPBK, Proposal, Sripsi, Tesis. Singaraja: BK FIP UNDIKSHA

(2015). RPBK Seri Bimbingan Klasikal, Bimbingan Kelompok, Konseling Kelompok, Konseling Individual untuk Pengembangan Mintat.Singaraja: BK FIP UNDIKSHA

Dantes, Nyoman. (2012). Metode Penelitian. Yogyakarta: CV Andi Offset

Damayanti, R., \& Aeni, T. (2016). Rika Damayanti, Tri Aeni, 3(1), 1-10. Retrieved from http://ejournal.radenintan.ac.id/index.php/konseli/article/view/572

Economia, N. D. I. (1997). La Valutazione Delle Performance Nelle Gestioni Museali : Problematiche Operative E Tecniche, 143-168. Retrieved from http://www.academia.edu/download/36338133/j6_chirieleison.pdf

Fran, S. (2007a)._Moun___ Retrieved from http://philosophiehaiti.org/wpcontent/uploads/2017/01/moun_5.pdf\#page=167

Fran, S. (2007b)._Moun 
Firdaus, M. Aziz. (2012). Metode Penelitian. Tanggerang Selatan: Jelajah Nusa

Gregory, R.J. (2000). Psychological Testing: History, Principles and Applications. Boston: Allyn \& Bacon

Gunarsa, D Singgih. (2004). Konseling dan Psikoterapi. Jakarta: PT BPK Gunung Mulia.

Gunawan, Muhammad Ali. (2013). Statistik untuk Penelitian Pendidikan. Yogyakarta: Parama Publising

Gh, S., Nampower, M., \& Rekeningkunde, S. D. (2012). Wat is die beste manier om maatskappye se finansiële nood te voorspel?, (2). Retrieved from http://alpa.maliit.eu/journal/aktet/vol/vol5/Aktet_Vol_V_Nr_2_pp_264_270.pdf

Giunta, A. A., \& Watson, L. T. (1998). A Comparison of Approximation Modeling Techniques: Polynomial Versus Interpolating Models. 7th AIAA/USAF/NASA/ISSMO Symposium on Multidisciplinary Analysis and Optimization, 1-13. https://doi.org/10.2514/6.1998-4758

Guillermo, R. (2010). Southeast Asian Robinsonades: A Study on the Translations of Joachim Heinrich Campe' s Robinson der Jüngere ( 1779 / 1780 ) into Tagalog ( Ang Bagong Robinson , 1879 ) and Bahasa Melayu ( Hikayat Robinson Crusoë , 1875 ), 177-192. Retrieved from http://www.apifellowships.org/body/international_ws_proceedings/09/P5-Ramon.pdf

Guirado, À. (2008). La superdotació als centres d'educació Infantil i Primària dels serveis territorials d'educació de Girona: Creences dels professionals de l'educació, mestres o equips d'assessorament i orientació psicopedagògica (EAP), sobre la detecció d'aquestes alumnes.

Giuseppe, P., Ottavio, G., Simone, C., \& Simone, F. (n.d.). Implementazione della Fuzzy Logic per la gestione ottimale del portafoglio : la modellizzazio ne dell ' avversione al rischio di un investitore attraverso tecniche di soft - computing, (1), 1-10. Retrieved from https://www.researchgate.net/profile/Pier_Giribone/publication/309637012_Implementazione_del la_Fuzzy_Logic_per_la_gestione_ottimale_del_portafoglio_la_modellizzazione_dell\%27avversione_a 1_rischio_di_un_investitore_attraverso_tecniche_di_soft-

computing/links/581b0ae908ae3c82664d5042/Implementazione-della-Fuzzy-Logic-per-la-gestioneottimale-del-portafoglio-la-modellizzazione-dellavversione-al-rischio-di-un-investitore-attraversotecniche-di-soft-computing.pdf

Had, V., \& Ad, S. (n.d.). Dobrovoljno i povjerljivo savjetovanje i testiranje na HIV.

Hoog, H. A. De. (n.d.). Du malsanoj en Esperanto.

Hoff, J., Kähler, N., \& Helgerud, J. (2006). Training sowie ausdauer- und krafttests von professionellen fußballspielern. Deutsche Zeitschrift Fur Sportmedizin, 57(5), 116-124. Retrieved from http://www.zeitschrift-sportmedizin.de/fileadmin/content/archiv2006/heft05/116-124.pdf

Juliansyah, Noor. (2011). Metodologi Penelitian. Jakarta: Kencana Perdana Media Group

Jumaquio-ardales, A. (2014). Pagdalumat sa Pamamahalang Pangwika ng Dalawang Arkipelagong Bansa : Ang Kaso ng Pilipinas at Indonesia sa Asya / Scrutinizing the Language Management of Two Archipelagic Countries: The Case of the Philippines \& Indonesia in Asia, 1, 69-83. Retrieved from http://www.academia.edu/download/37411501/PHINDO.Ardales.pdf

Kroff, J. (2005). The Relationship Between Respiratory Muscle Fatigue , Core Stability , Kinanthropometric Attributes and Endurance Performance in, (April). Retrieved from http://scholar.sun.ac.za/handle/10019.1/1790

Komalasari, Gantina dkk. (2011). Teori dan Teknik Konseling. Jakarta Barat: Permata Puri Media.

Koyan, Wayan. 2012. Statistik Pendidikan, teknik analisis data kuantitatif. Singaraja: Universitas Pendidikan Ganesha Press

Mar, A., Hasanah, A., \& Saraswati, S. (2014). Indonesian Journal of Guidance and Counseling: Theory 
and Application. Indonesian Journal of Guidance and Counseling: Theory and Application, 3(4), 3946.http://psycnet.apa.org/journals/cou/43/3/310/

Mengalami, Y., Identitas, G., \& Gig, G. (n.d.). SCHEMA - Journal of Psychological Research , Hal. 2334, 23-34.http://psycnet.apa.org/journals/met/4/3/272/

Narbuko, Cholid., dan Achmadi, Abu. (2013). Metodologi Penelitian. Jakarta: PT Bumi Aksara

Nasution. (2008). Metode Research (penelitian ilmiah). Jakarta: PT Bumi Aksara

Not, T. (2008). Mentalna retardacija: definicija, klasifikacija i suvremena podrška osobama s intelektualnim teškoćama, 339-351. Retrieved from http://hrcak.srce.hr/34567

Pedagogika. (2007), 1-182. Retrieved from https://www.ceeol.com/content-files/document-214613.pdf

Picone, J. . (1993). Signal Modeling Techniques in Speech Recognition. Proceedings of the IEEE, 81(8), 1215-1247. https://doi.org/10.1109/5.237532

Ponce, M. J. (2008). Philippine Studies. Philippine Studies, Volume 56(No. 1), 77-101. Retrieved from http://www.philippinestudies.net/files/journals/1/articles/2916/public/2916-3191-1-PB.pdf

Reksoatmodjo, Tedjo N. (2009). Statistika untuk Psikologi dan Pendidikan.Bandung: PT Refika Aditama Rollnick, S., \& Miller, R. (2003). Det motiverende interview, (2), 1-6. Retrieved from http://www.acp-italia.it/rivista/2004/Francesca_calvano_-

_la_definizione_anglosassone_di_counseling.pdf

Setyosari, Punaji. (2012). Metode Penelitian Pendidikan dan Pengembangan.Jakarta: Kencana Prenada Media Group

Sintadewi, Ni Luh Dian. (2014). "Efektivitas Model Konseling Behavioral Teknik Modeling Untuk Meningkatkan Efikasi Diri Siswa Kelas VIII SMP Negeri 2 Singaraja Tahun Pelajaran 2013/2014". Jurnal Bimbingan Konseling, Volume: 2 No 1, Tahun 2014

http://ejournal.undiksha.ac.id/index.php/JJBK/article/view/3727

Sinolungan, A. E. (2001). Psikologi Perkembangan Peserta Didik. Manado: PT. Gunung Agung

Sudaryono, dkk. (2013). Pengembangan Instrumen Penelitian Pendidikan. Yogyakarta: Graha Ilmu

Sudrajat, Ahmad. (2008). Pendekatan Konseling Behavioral. Diakses melalui: https:/akhmadsudrajat.wordpress.com/2008/01/23/ pendekatan-konseling-behavioral/ Pada tanggal : 1 Desember 2015

Suharsaputra, Unhar. (2012). Metode Penelitian kuantitatif, kualitatif dan tindakan.Bandung: PT Refika Aditama

Sukardi. (2012). Metodelogi Penelitian Pendidikan Kompetensi dan Praktiknya.Jakarta: PT Bumi Aksara

Sutama, Gede Agus. (2014). "Penerapan Teori Behavioral dengan Teknik Modeling untuk Meningkatkan Kemandirian Belajar Pada Siswa Kelas XI AK C di SMK Negeri 1 Singaraja". Jurnal Bimbingan Konseling, Volume: 2 No 1, Tahun 2014

http://ejournal.undiksha.ac.id/index.php/JJBK/article/view/3960

Sampieri, R. H., Collado, C. F., \& Lucio, P. B. (2006). Metodologia de.

Schmidt, W., Prommer, N., Steinacker, J. M., \& Boning, D. (2006). Sinn und Unsinn von h??matologischen Grenzwerten im Ausdauersport - Folgerungen aus den Dopingskandalen von Turin 2006. Deutsche Zeitschrift Fur Sportmedizin, 57(2), 54-56. Retrieved from http://www.zeitschriftsportmedizin.de/fileadmin/content/archiv2006/heft02/54-56.pdf 
Stamina, V. L. (2014). Die krag van uithouvermoë, (1). Retrieved from http://scholar.sun.ac.za/bitstream/handle/10019.1/96508/smith_krag_2014.pdf?sequence=1

Whitlock, E. P., Orleans, C. T., Pender, N., \& Allan, J. (2002). Evaluating primary care behavioral counseling interventions - An \nevidence-based approach. American Journal of Preventive Medicine, 22(4), 267-284. https://doi.org/10.1016/S0749-3797(02)00415-4

Article Information (Supplementary)

Conflict of Interest Disclosures:

The authors declare that they have no significant competing financial, professional or personal interests that might have influenced the performance or presentation of the work described in this manuscript.

Copyrights Holder: Dewa Gede Agung Permana Putra, Dewi Arum WMP, I Ketut Dharsana 2017

First Publication Right: BISMA The Journal of Counseling

https://doi.org/10.23887/128332017

Open Access Article | CC-BY Creative Commons Attribution 4.0 International License.

Word Count: 